\title{
Petroleum Hydrocarbon Compound
}

National Cancer Institute

\section{Source}

National Cancer Institute. Petroleum Hydrocarbon Compound. NCI Thesaurus. Code C122495.

Any chemical compound that is derived from crude oil. Petroleum hydrocarbon compounds can enter the environment through accidents, industrial releases, or as byproducts of commercial or private uses. 